\title{
Análise de Insolvência das Cooperativas de Crédito Rural do Estado de Minas Gerais
}

\author{
Valéria Gama Fully Bressan Mestre em Economia Aplicada, Professora Substituta, \\ Universidade Federal de Minas Gerais \\ Marcelo José Braga \\ DS em Economia Rural, Professor Adjunto, Universidade \\ Federal de Viçosa, Bolsista do CNPq. Professor Visitante, \\ Universidade da Califórnia, em Davis \\ João Eustáquio de Lima \\ PhD em Economia Agrícola, Professor Titular, \\ Universidade Federal de Viçosa
}

\section{RESUMO}

O cooperativismo de crédito rural é uma alternativa que possibilita ao produtor facilidades na obtenção de financiamento. A redução do volume de Crédito Rural oficial e a implementação do Plano Real provocaram mudanças no sistema financeiro. Nesse contexto, buscou-se avaliar, a partir da estrutura financeira, se as cooperativas de crédito encontram-se em estado de solvência ou insolvência, por meio da verificação de seus indicadores financeiros. Empregou-se o modelo Logit e a área de estudo envolveu as cooperativas do Estado de Minas Gerais, no período de 1998 a 200I. Constatou-se que os indicadores importantes para predição de insolvência foram capitalização, cobertura voluntária e crescimento da captação total. Verificou-se, em agosto de 2001 , que $98,06 \%$ das cooperativas de crédito rural do Estado de Minas Gerais estavam solventes, o que indica a importância e efetividade do sistema em atender às demandas de crédito por parte do produtor rural.

\section{PALAVRAS-CHAVE}

cooperativismo de crédito, avaliação financeira, insolvência, modelo Logit

ABSTRACT

Credit unions are an alternative to make possible to the agricultural producer access for credit obtaining. The reduction of the official agricultural loan program and the implementa-

tion of the monetary stabilization plan of 1994 caused changes in the Brazilian financial system. So, the objective of this study was to evaluate, from the financial structure, the state of solvency of the rural credit unions, by the verification of financial indicators. It was used the Logit Model and the sample was formed from the credit unions of the Minas Gerais State, Brazil, between 1998 and 200I. The results indicated that the relevant ratios for insolvency prediction were capitalization, volunteer covering e total capitation growth. It was also verified that, in august $2001,98,6 \%$ of the agricultural credit cooperatives were in sol-

vency state, suggesting the importance and effectiveness of system as a supplier for the credit needs of the agricultural producers.

KEY WORDS credit cooperative, financial evaluation, insolvency, Logit model

JEL Classification

Q13, Q/4

EST. ECON., SÃO PAULO, V. 34, N. 3, P. 553-585, JULHO-SETEMBRO 2004 


\section{INTRODUÇÃO}

A concessão de financiamento mediante crédito rural, com a criação, em 1965, do Sistema Nacional de Crédito Rural (CNCR), representou um marco para o setor agropecuário e viabilizou financiamentos aos produtores, permitindo que eles se capitalizassem. No entanto, a partir do final dos anos 70 esse sistema apresentou sérios problemas de operacionalização, como o desequilíbrio entre as fontes de captação de recursos e as demandas colocadas pelos interessados. Sob a ótica produtivista, comprovou-se a ineficácia dos elevados volumes de recursos para o financiamento da produção, além das distorções fundiárias e sociais provocadas pela utilização discriminatória do crédito rural. (BELIK \& PAULILLO, 2002).

Nos anos 90, com o acirramento da crise fiscal e financeira do Estado, a perspectiva alterou-se, dadas as políticas fundamentadas em instrumentos mais adequados à nova realidade econômica e financeira do País. (CARVALHO, 2000). Nesse sentido, Gasques e Vila Verde (1996) destacam que o centro das preocupaçóes dos produtores passou a ser a busca de novas fontes de recursos capazes de atender às necessidades de financiamento, uma vez que se esgotou o modelo baseado nas exigibilidades e nas emissões de títulos e de moeda.

Dessa forma, o produtor passou a recorrer a outras fontes de financiamento como: a) Compra antecipada, instrumento articulado pela agroindústria que se financia no exterior ou por meio de ACCs (Adiantamento de Contratos de Câmbio), que repassa os recursos para os agricultores com a compra antecipada da produção; b) Cédula do Produto Rural (CPR), títulos emitidos pelos produtores ou pelas cooperativas e negociados em bolsa ou bilateralmente, garantindo recursos antecipados para o custeio; c) FINAME Agrícola, operado pelo BNDES, proporciona financiamento para o investimento em máquinas agrícolas e instalações; d) Contrato de Investimento Coletivo (CIC), captação de recursos de um grupo de investidores que participam dos lucros advindos da engorda de gado e das eventuais valorizações ou desvalorizações das cotações do produto; e e) Pregões Eletrônicos, instrumento que procura aproximar produtores de consumidores e cujo papel é estabelecer contatos diretos entre compradores e vendedores. (BELIK \& PAULILLO, 2002). 
Outra alternativa para o produtor rural foi a constituição de cooperativas de crédito rural, que, segundo Berzoini e Souza (2001), tem sido viável para o financiamento do pequeno produtor, tanto o rural quanto o urbano, em alguns dos principais países desenvolvidos. Destacaram estes autores que a estrutura de pequenas cooperativas de crédito sem fins lucrativos, do sistema financeiro cooperativo na Europa e no Canadá, tem desempenhado papel importante, ao provocar a queda das taxas de juros, quebrando o oligopólio dos grandes conglomerados financeiros nas regióes onde atua.

No sistema financeiro brasileiro, em particular, diversos papéis poderiam ser atribuídos a um sistema financeiro cooperativo. Dentre eles, o papel de "desintermediadora" financeira, pois parcela dos recursos financeiros dos produtores, ou dos associados das cooperativas, que anteriormente era intermediada pelos bancos, passa a ser feita por meio das cooperativas de crédito. Segundo Carcanholo (2002), a "desintermediação" implica a abolição da intermediação, bancária ou não-bancária, nas operações de crédito. Trata-se de uma operação direta de crédito entre o aplicador e o tomador, efetuada por negociação de títulos ou ações (processo de securitização). Essa definição realça o papel da cooperativa nesse sistema de "desintermediação", pois os associados são, ao mesmo tempo, dono e usuário das cooperativas e beneficiam-se dos rendimentos das transaçôes financeiras que seriam destinados aos intermediários.

Mas, para que as cooperativas possam realmente atender às necessidades financeiras dos produtores rurais é importante que tenham estrutura financeira sólida, com baixos riscos de insolvência. Verificou-se que, em decorrência do Plano Real, dos 271 bancos existentes no início do Plano Real 50 passaram por algum tipo de intervenção. (ROCHA, 1999). Torna-se importante avaliar, neste contexto, como se encontra a situação desse ramo do cooperativismo, visto que pertence ao sistema financeiro nacional

Avaliar a estrutura de instituições financeiras tem sido uma prática que vem se ampliando nas últimas décadas, pelo fato de: 1) Auxiliar as empresas seguradoras; 2) Fornecer subsídios às políticas e intervenções por parte de bancos centrais; 3) Por ser um mecanismo utilizado para verificar a capacidade de pagamento dessas instituiçõoes diante de obrigaçóes contraídas com outras instituições financeiras; e 4) Auxiliar o administrador financeiro a 
controlar a situação da empresa. Esta avaliação permite determinar qual é a situação financeira da empresa, possibilitando maior segurança aos demais agentes econômicos, uma vez que incorrem em menor risco ao operarem com empresas ou instituições cuja saúde financeira é conhecida. (ROLANDO et al., 1981).

Nesse sentido, o objetivo deste trabalho é avaliar a situação econômico-financeira das cooperativas de crédito de crédito rural no Estado de Minas Gerais com o intuito de fornecer subsídio ao trabalho de monitoramento dessas cooperativas pelos órgãos de apoio do sistema cooperativista.

\section{INSOLVÊNCIA E SOLVÊNCIA}

De acordo com Mora (1994), citado por Gimenes (1998), não há uma metodologia única para a construção de modelos de previsão de insolvência e também não há um consenso teórico sobre qual das metodologias é a melhor. Assaf Neto (1981) enfatiza que desde que a insolvência seja um processo real e identificável nos balanços é perfeitamente possível desenvolver alguma técnica para descobrir os seus sintomas característicos e orientar as cooperativas, com vistas a efetuar algum remanejamento de atuação e adequação.

Kanitz (1978) cita a existência de vários estudos que mostram que as empresas insolventes começam a acusar sinais de dificuldades bem antes de chegar ao ponto crítico de uma falência ou concordata, e que talvez seja impossível prever uma falência com $100 \%$ de certeza, mas é perfeitamente possível identificar aquelas que têm maiores possibilidades de falir em futuro não muito distante. Para ele, são as pequenas e médias empresas as que estão mais expostas à insolvência

Segundo Gitman (1997), a insolvência ocorre quando a empresa é incapaz de pagar suas obrigações em seu vencimento. Para Altman (1968), a insolvência de uma empresa é declarada quando os acionistas recebem por suas

ações rentabilidade menor que a oferecida pelo mercado, que trabalha com ações similares. 
Gimenes (1998) considera estado de insolvência quando a empresa declara a suspensão de pagamentos ou quebra, ou seja, quando não pode honrar suas dívidas com os credores. Por sua vez, para Matias (1978), citado por Silva (1983), as empresas insolventes são aquelas que tiveram processos de concordata requerida e/ou deferida e/ou falência decretada.

A insolvência é um processo prolongado de declínio e uma espiral descendente, não é um evento discreto. (DAILY \& DALTON, 1994). Matias e Siqueira (1996) conceituaram insolvência como o fato de a instituição sofrer liquidação ou intervenção do Banco Central. De acordo com Tzirulnik (1997), a intervenção só poderá ser realizada se forem verificadas anormalidades nos negócios sociais da instituição financeira. A lei prevê as seguintes anormalidades: má administração, infrações a dispositivos bancários e impontualidade e/ou presunção de insolvência.

Janot (2001) considera que uma instituição financeira se torna insolvente quando seu patrimônio líquido se torna negativo ou se for impossível continuar suas operações sem incorrer em perdas que resultariam em patrimônio líquido negativo. Destaca também que outra forma de definir insolvência é quando essa instituição é colocada em evidência pelo supervisor responsável; no entanto, esse tipo de abordagem apresenta desvantagem, por depender de critérios subjetivos de julgamento. "Por outro lado, como a colocação de um banco em evidência precede sua liquidação, um modelo que preveja esta classificação provê um tempo maior para açôes corretivas.” (JANOT, 1999, p. 3).

Segundo Sundararajan e Balino (1991), citados por Pandeló Jr. (1997), a insolvência em instituição financeira ocorre quando esta apresenta valor presente líquido negativo, com base no fluxo de caixa de suas operações passivas. Apesar da aparente simplicidade, o cálculo ou a mensuração do valor presente líquido negativo de uma instituição financeira não é tarefa fácil, pois a avaliação deve ser feita com base no valor de mercado das operaçôes, o qual, normalmente, difere do valor contábil destas. (GLAUESSNER \& MAS, 1995, citados por PANDELÓ JR., 1997). O valor presente líquido negativo reflete, portanto, uma situação em que o valor de mercado dos ativos de uma instituição é menor do que o valor de mercado dos seus passivos. (DEMIRGUÇ-KUNT, 1989, citado por PANDELÓ JR., 1997). 
Casos extremos de liquidez insuficiente podem acarretar a insolvência de um banco. O risco de liquidez de um banco decorre da sua capacidade de promover reduções em seu passivo ou financiar acréscimos em seus ativos. Quando um banco apresenta liquidez inadequada, perde a capacidade de obter recursos, seja por meio de um aumento de seus exigíveis, seja pela pronta conversão de seus ativos, a custos razoáveis, afetando, assim, a rentabilidade. Desta forma, a finalidade da administração de liquidez é assegurar que o banco seja capaz de cumprir, integralmente, todos os compromissos contratuais. Os elementos fundamentais para uma sólida administração de liquidez incluem um bom sistema de administração de informações, controle central da liquidez, análise das necessidades líquidas de financiamento sob cenários alternativos, diversificação das fontes de financiamento e plano de contingências. ${ }^{l}$ (BCB, 2001).

As empresas, uma vez insolventes, podem chegar à falência, e, de acordo com Schumpeter (1939), citado por Altman et al. (1979), nos sistemas econômicos em que as firmas podem entrar e sair sem barreiras artificiais o fenômeno negativo dito falência é normal. Mesmo nos sistemas em que existe considerável influência do governo nas forças de mercado, falências ocasionais não devem causar preocupação. No entanto, a previsão dessas ocorrências proporciona óbvios benefícios, especialmente se puder ser feita a tempo de se tomar uma ação corretiva.

Com relação às causas que podem contribuir para um estado de insolvência, têm-se diversas abordagens na literatura econômica. Para Muñoz (2001), são as condições econômicas e as medidas políticas que exercem influência na situação de solvência ou insolvência. Com relação aos bancos, destaca que a insolvência ocorre devido a fatores como fraudes, imprudência administrativa, ocorrência de prejuízos consecutivos, além da influência dos aspectos macroeconômicos. Gimenes (1998) aponta causas de origem externa como forte queda de demanda, fase depressiva da economia, crises econômicas, políticas governamentais, mudanças sociais radicais e significantes. Destaca também causas internas, como ineficácia da direção, estratégias er-

1 O Comitê da Basiléia emitiu um documento que define os principais elementos de uma estrutura modelo analítica para medição e gestão de liquidez. Embora o documento enfoque o uso da estrutura por bancos grandes e internacionais ativos, ele fornece orientaçóes que podem ser úteis para todos os bancos. Ver $A$ framework for measuring and managing liquidity ("Um esquema para medir e gerenciar a liquidez"), Volume 1 do compêndio. 
rôneas e inadequadas, além de sistema produtivo ineficiente, endividamento excessivo, alta morosidade, entre outros.

Vários autores, avaliando a situação de insolvência e de falência por meio de indicadores financeiros, constataram, os seguintes indicadores como significativos (ver Quadro 1).

Backer e Gosman (1978) consideram como parâmetros para insolvência a análise de debêntures, o crédito comercial e os empréstimos bancários. Merwin (s.d.), citado por Silva (1988), ao desenvolver estudo com pequenas sociedades anônimas manufatureiras (ativos totais abaixo de US\$ 250.000), e examinar apenas três tipos de índices, concluiu que o capital de giro sobre o ativo total foi o melhor indicador de falência.

Kanitz (1978) construiu o chamado "termômetro de insolvência", seguindo uma linha semelhante à de Altman (1968), e utilizou como fator de insolvência os seguintes indicadores, multiplicados por pesos que foram estipulados com base em ponderaçôes estatísticas: (1) lucro líquido sobre patrimônio líquido recebeu peso 0,05 ; (2) ativo circulante mais realizável no longo prazo sobre exigível total foi ponderado por 1,65 ; (3) ativo circulante menos estoque sobre passivo circulante (liquidez seca) foi multiplicado por 3,55 ; (4) ativo circulante sobre passivo circulante (liquidez corrente) recebeu peso 1,06; e (5) exigível total sobre patrimônio líquido foi ponderado por 0,33 . O fator de insolvência foi definido como $(1)+(2)+(3)-(4)-$ (5) e apresenta variaçốes abaixo e acima de zero. Os valores abaixo de -3 indicam que a empresa encontra-se numa situação que poderá levá-la à falência. Evidentemente, quanto menor esse valor, mais próxima da falência estará a empresa. A área do "termômetro de insolvência", compreendida entre 0 e -3 , é o que se chamou de "penumbra", ou seja, uma área em que a indicação do fator de insolvência não é suficiente para determinar a situação da empresa. Entretanto, o uso de maior número de índices para calcular o fator de insolvência ajuda a diminuir essa zona de penumbra no termômetro. Os valores acima de zero representam insolvência positiva (solvência), e os menores, possibilidades de vir a falir. Essa possibilidade diminuirá à medida que o fator positivo for maior. 
QUADRO 1 - AUTORES QUE TRATARAM A QUESTÃO DE INSOLVENNCIA E FALENCIA, E OS RESPECTIVOS INDICADORES FINANCEIROS SIGNIFICATIVOS PARA AVALIAR ESSES EVENTO

\begin{tabular}{|c|c|c|}
\hline Autores & $\begin{array}{l}\text { Evento } \\
\text { estudado }\end{array}$ & Indicadores Financeiros \\
\hline $\begin{array}{l}\text { Patrick (1936), apud } \\
\text { Silva (1983) }\end{array}$ & Falência & $\begin{array}{l}\text { Patrimônio Líquido/Passivo } \\
\text { Lucro líquido/Patrimônio Líquido }\end{array}$ \\
\hline $\begin{array}{l}\text { Winakor e Smith (sd), } \\
\text { apud Silva (1983) }\end{array}$ & Falência & Capital de giro/ativo total \\
\hline $\begin{array}{l}\text { Tamari (sd), apud } \\
\text { Silva (1988) }\end{array}$ & Falência & $\begin{array}{l}\text { Lucro } \\
\text { Capital social + Reservas/Passivo Total }\end{array}$ \\
\hline $\begin{array}{l}\text { Beaver (1968), apud } \\
\text { Silva (1988) }\end{array}$ & Falência & $\begin{array}{l}\text { Geração de Caixa/dívida total } \\
\text { Lucro líquido/ativo total } \\
\text { Exigível total/ativo total } \\
\text { Capital de giro/ativo total } \\
\text { Liquidez corrente } \\
\text { Capital circulante líquido - estoques/desembolsos operacionais } \\
\text { previstos. }\end{array}$ \\
\hline Altman (1968) & Falência & $\begin{array}{l}\text { Ativo corrente - Passivo corrente/ativo total } \\
\text { Lucros retidos/ativo total } \\
\text { Lucros antes de juros e impostos/ativo total } \\
\text { Valor de mercado do equity²/exigível total } \\
\text { Vendas/ativo total }\end{array}$ \\
\hline $\begin{array}{l}\text { Matias (1978), apud } \\
\text { Silva (1983) }\end{array}$ & Insolvência & $\begin{array}{l}\text { Patrimônio líquido/ativo total } \\
\text { Financiamento e empréstimos bancários/ativo circulante } \\
\text { Fornecedores/ativo total } \\
\text { Ativo circulante/passivo circulante } \\
\text { Lucro operacional/lucro bruto } \\
\text { Disponível/ativo total }\end{array}$ \\
\hline Kanitz (1978) & Insolvência & $\begin{array}{l}\text { Lucro líquido/patrimônio líquido } \\
\text { Ativo circulante + realizável a longo prazo/exigível total } \\
\text { Ativo circulante - estoque/passivo circulante Ativo circulante/ } \\
\text { passivo circulante } \\
\text { Exigível total/patrimônio líquido. }\end{array}$ \\
\hline $\begin{array}{l}\text { Matias e Siqueira } \\
(1996)\end{array}$ & Insolvência & $\begin{array}{l}\text { Custo administrativo } \\
\text { Comprometimento do patrimônio líquido com crédito em liquida- } \\
\text { ção } \\
\text { Evolução da captação de recursos }\end{array}$ \\
\hline Rocha (1999) & Insolvência & Margem líquida \\
\hline Martins (2003) & $\begin{array}{l}\text { Insolvên- } \\
\text { cia (con- } \\
\text { cordata) }\end{array}$ & $\begin{array}{l}\text { Empréstimos bancários/ativo circulante } \\
\text { Retorno sobre o patrimônio líquido }\end{array}$ \\
\hline
\end{tabular}

Fonte: Elaborado pelos autores.

2 Valor de mercado do equity é o número de ações a preço de mercado.

Est. econ., São Paulo, 34(3): 553-585, jul-set 2004 
Almeida (1993), ao discuta a evolução dos riscos de falência em empresas, considera que a metodologia para avaliar esses riscos divide-se em quatro pontos: 1) Construção de uma amostra que contenha empresas solventes e insolventes; 2) Importância de selecionar variáveis que indicarão o fenômeno em questão, com base nas demonstrações financeiras das empresas, denominado pelo autor de variáveis discriminantes; 3) Seleção de um modelo ou técnica estatística que permita modelar as variáveis extraídas das demonstrações financeiras, a exemplo da análise discriminante e da análise logística; e 4) Validação do modelo para verificação da capacidade discriminante do modelo.

O autor supracitado destaca que a definição do critério para determinar a falência é outro elemento importante para a constituição da amostra. Relata, ademais, que alguns pesquisadores consideram como falidas as empresas ilíquidas; outros, as que cessarem seus pagamentos; outros, as que suspenderam depósitos de dividendos prioritários; e, outros, as que não registrarem suas perdas. Além disso, enfatiza a questão da ausência de uma teoria que explique, de maneira rigorosa, os processos de falência.

Constata-se que não há consenso sobre quais indicadores são mais relevantes para determinar ou não a insolvência de um banco ou empresa, assim como para indicar a falência. Gimenes (1998) destaca a ausência de uma teoria econômica que subsidie a escolha das variáveis para previsão de insolvência. No entanto, esse fator não impede que sejam elaborados indicadores objetivos de análise para avaliar e prever a situação de insolvência ou falências. Dessa forma, conclui-se que não há uma definição única que caracterize insolvência.

Com relação à solvência, Matias (1978), citado por Silva (1983), considera que empresas solventes são aquelas que desfrutam de crédito amplo pelo sistema bancário, sem restrições a financiamentos ou empréstimos. Pode-se fazer uma extrapolação para o sistema bancário, considerando-se que os bancos estariam solventes se o banco central e demais bancos fornecessem créditos sem restrições, além de possuírem recursos para atender a seus clientes. 
De acordo com Assaf (1989), citado por Albuquerque Jr. e Ribeiro (2001), a solvência de um banco ocorreria quando o valor de seus ativos excedesse o valor de seus passivos, de diferentes naturezas, formando um excedente chamado patrimônio líquido. Esse volume de capital próprio funciona como uma reserva para eventuais perdas de valor de seus ativos. A solvência evidencia os recursos próprios de uma instituição como suporte ao risco que esta está sujeita em seu ramo de atividade.

De acordo com o Manual da Austin Asis, ${ }^{3}$ citado por Matias e Siqueira (1996), os indicadores que determinam a solvência são encaixe, cobertura voluntária, solvência corrente, assistência financeira, adequação de prazos, inadimplência, provisionamento e comprometimento.

Para Kanitz (1978), a análise do índice de solvência permite: a) Descobrir empresas em estado de pré-insolvência; b) Hierarquizar as empresas numa escala de solvência/insolvência, a fim de selecionar clientes prioritários; e c) Determinar previsões para conta "devedores duvidosos", segundo a probabilidade de cada cliente. Destaca também que, ao contrário do que se costuma pensar, os índices de liquidez não são um indicador seguro do estado de solvência das empresas e aponta os seguintes indicadores como os mais importantes:

Capital de giro próprio: as empresas financeiramente sólidas, em geral, dispõem de recursos próprios suficientes para financiar pelo menos parcela de seus investimentos em ativo fixo e, ainda, parte de seu capital de giro. É o que se denomina de capital de giro próprio. As empresas insolventes, porém, tendem a trabalhar, exclusivamente, com capital de terceiros.

Grau de endividamento: esse indicador serve para caracterizar um ciclo vicioso. Por não disporem de recursos próprios, as empresas insolventes apresentam, invariavelmente, elevado grau de endividamento, pelo menos um ou dois anos antes da falência ou concordata. Na verdade, ela está contraindo dívidas para pagar dívidas, ao contrário de uma empresa solvente, que

3 Este manual foi elaborado pela empresa Austin Asis, especializada em risco bancário, e contém indicadores para realizar análise financeira. 
busca no endividamento o indispensável complemento dos recursos próprios para realizar investimentos produtivos.

Rentabilidade do patrimônio líquido: nas empresas insolventes, este índice geralmente é baixo. Entretanto, uma empresa bem administrada pode aguentar prejuízos durante algum tempo e, ainda assim, recuperar-se. No entanto, firmas com boa rentabilidade sobre o patrimônio (em outras palavras, com bom lucro líquido) também podem falir. Neste caso, não basta analisar os índices mencionados anteriormente; é preciso atentar-se para outros dois índices:

- Ativo fixo sobre patrimônio líquido, que revela se a empresa não está investindo além de suas possibilidades. Geralmente isto ocorre com empresas que já têm boa parte do seu capital imobilizado em instalações antigas e, ao mesmo tempo, estão investindo em novos equipamentos e na ampliação das instalações atuais. Quando o ativo fixo for $100 \%$ maior que o patrimônio líquido, a empresa estará se descapitalizando perigosamente e abrindo caminho para a insolvência, mesmo que tenha lucros elevados; e

- Ativo circulante sobre ativo fixo, quando este índice é alto, a empresa está financiando demais as suas vendas ou mesmo seus clientes, o que indica que a falência de um cliente pode levar o fornecedor pelo mesmo caminho.

\subsection{Determinantes da Condição de Insolvência}

Com o objetivo de detectar se as cooperativas de crédito rural de Minas Gerais encontravam-se ou não insolventes e de possibilitar aos dirigentes e à cooperativa central a tomada de medidas corretivas que evitem a insolvência ou, pelo menos, minimizem suas perdas, será especificado o modelo de Análise de Regressão Logística, para variável dependente dicotômica, que terá valor 1 , quando a cooperativa for classificada como insolvente e 0 , caso contrário. 
Essa técnica permite estimar a probabilidade de ocorrência de um evento e identificar as variáveis independentes que contribuem para a sua predição. $\mathrm{O}$ modelo de regressão logística é o mais apropriado no caso de a variável binária ser dicotômica, segundo Norusis (1993), citado por Matias e Siqueira (1996). O emprego deste modelo na análise de bancos também está consolidado na literatura, conforme mostram especialmente os trabalhos de Martin (1977), Espahbodi (1991), Matias e Siqueira (1996), Rocha (1999), Janot (2001) e Albuquerque Jr. e Ribeiro (2001).

Com o modelo logit estima-se, diretamente, a probabilidade de ocorrência de um evento. De acordo com Kennedy (1994), a estimação do modelo logit pode ser feita de duas formas. No primeiro caso,

$$
\hat{\mathrm{P}}_{\mathrm{i}}=\frac{\mathrm{n}_{\mathrm{i}}}{\mathrm{N}_{\mathrm{i}}}
$$

em que $\hat{\mathrm{P}}_{\mathrm{i}}=$ probabilidade de as cooperativas de crédito rural estarem insolventes; ni = número de cooperativas insolventes; e $\mathrm{N}_{\mathrm{i}}=$ número total de cooperativas, para cada observação i.

Este é usado quando há grande número de observações que podem ser reunidas em grupos de observações com indivíduos de características semelhantes. Assim, pode-se estimar a freqüência relativa das cooperativas que se encontravam insolventes, calculando a sua porcentagem pela equação (1).

Nesse caso, os termos de erro da regressão serão heteroscedásticos, devendose utilizar os mínimos quadrados generalizados para correção do problema.

No segundo caso, dada a composição dos dados disponíveis, $\hat{\mathrm{P}}_{\mathrm{i}}$ não pode ser encontrado pela equação ( 1 ); admite-se, então, valor 0 , quando a cooperativa estiver solvente, e 1, quando estiver insolvente. Assim, o modelo logit é estimado por Máxima Verossimilhança, que será utilizada neste trabalho.

A função de densidade de probabilidade acumulada logística pode ser definida pela equação:

$$
F(\theta)=\frac{e^{\theta}}{\left(1+e^{\theta}\right)}
$$


Esta função varia de zero a um, com $\theta$ variando de menos infinito a mais infinito. Ao substituir $\theta$ por $\mathrm{X} \beta$, o modelo logístico específico, para análise econométrica da probabilidade de insolvência, pode ser dado por:

$$
\operatorname{prob}(\mathrm{Y}=1)=\frac{\mathrm{e}^{\mathrm{x} \beta}}{1+\mathrm{e}^{\mathrm{x} \beta}}
$$

em que $\operatorname{prob}(\mathrm{Y}=1)=$ probabilidade de a cooperativa estar insolvente; $\mathrm{x}=$ variáveis independentes ou fatores que explicam a probabilidade de insolvência; $\beta=$ parâmetros a serem estimados; e e = base do logaritmo natural.

O que implica que há probabilidade de a cooperativa não estar insolvente será:

$$
\operatorname{prob}(\mathrm{Y}=0)=1-\operatorname{prob}(\mathrm{Y}=1)=\frac{1}{1+\mathrm{e}^{\mathrm{x} \beta}}
$$

em que $\operatorname{prob}(\mathrm{Y}=0)=$ probabilidade de não estar insolvente.

A função de Máxima Verossimilhança é dada por

$$
L=\prod_{i} \frac{e^{x_{i} \beta}}{1+e^{x_{i} \beta}} \prod_{j} \frac{1}{1+e^{x_{j} \beta}}
$$

em que $i$ diz respeito às cooperativas insolventes, $\mathrm{e} j$, àquelas que não estão insolventes.

Maximizando essa função em relação ao vetor $\beta$, têm-se as estimativas de Máxima Verossimilhança para $\beta$. Para $n$ cooperativas, tem-se que a probabilidade de estar insolvente é dada por:

$$
P(Y=1)=\frac{e^{x^{\prime} \beta}}{1+e^{x^{\prime} \beta}}
$$

A equação (6), para o modelo LOGIT, sugere que:

$$
\frac{\operatorname{prob}(\mathrm{Y}=1)}{\operatorname{prob}(\mathrm{Y}=0)}=\mathrm{e}^{\mathrm{x} \beta}
$$


então,

$$
\ln \left(\frac{\operatorname{prob}(Y=1)}{\operatorname{prob}(Y=0)}\right)=x \beta \text {. }
$$

O modelo aplicado a esta pesquisa será definido da seguinte forma:

$$
\begin{aligned}
& \ln \left(\frac{\mathrm{P}(\mathrm{Y}=1)}{\mathrm{P}(\mathrm{Y}=0)}\right)=\beta_{0}+\beta_{1} \mathrm{CAP}_{\mathrm{i}}+\beta_{2} \text { IMOB }_{\mathrm{i}}+\beta_{3} \mathrm{CG}_{\mathrm{i}}+\beta_{4} \text { ALAV }_{\mathrm{i}}+ \\
& +\beta_{5} \mathrm{ENC}_{\mathrm{i}}+\beta_{6} \text { COBVOL }_{\mathrm{i}}+\beta_{7} \text { VOLCRED }_{\mathrm{i}}+\beta_{8} \text { DESPES }_{\mathrm{i}}+ \\
& +\beta_{9} \text { DESPADM }_{\mathrm{i}}+\beta_{10} \text { DESPTOTAL }_{\mathrm{i}}+\beta_{11} \text { GERARENDA }_{\mathrm{i}}+ \\
& +\beta_{12} \text { CAPLITOTAL }_{\mathrm{i}}+\beta_{13} \text { CCAPTOTAL }_{\mathrm{i}}+\beta_{14} \text { CRECOPER }_{\mathrm{i}}+ \\
& +\beta_{15} \text { LG }_{\mathrm{i}}+\varepsilon_{\mathrm{i}}
\end{aligned}
$$

em que ln é o logaritmo natural; $\mathrm{P}(\mathrm{Y}=1)$ = probabilidade de a cooperativa estar insolvente; $\mathrm{P}(\mathrm{Y}=0)$ = probabilidade de a cooperativa estar solvente; $\mathrm{CAP}_{\mathrm{i}}=$ capitalização para cada observação $\mathrm{i} ; \mathrm{IMOB}_{\mathrm{i}}=$ imobilização para cada observação i; $\mathrm{CG}_{\mathrm{i}}=$ capital de giro para cada observação i; $\mathrm{ALAV}_{\mathrm{i}}=$ alavancagem para cada observação $i ; \mathrm{ENC}_{i}=$ encaixe para cada observação i; COBVOL $_{i}=$ cobertura voluntária para cada observação $i$ LG $_{i}=$ liquidez geral para cada observação $i$ VOLCRED $_{i}=$ volume de crédito em relação ao patrimônio líquido para cada observação $i$; DESPES $_{\mathrm{i}}=$ despesas com pessoal para cada observação $i ; \operatorname{DESPADM}_{\mathrm{i}}=$ despesas administrativas para cada observação $\mathrm{i}$; DESPTOTAL $\mathrm{D}_{\mathrm{i}}=$ despesas totais para cada observação i; GERARENDA $A_{i}=$ geração de renda para cada observação i; CAPLICTOTAL $_{\mathrm{i}}=$ crescimento das aplicações totais para cada observação i; CCAPTOTAL $_{i}=$ crescimento das captações totais para cada observação i; CRECOPER $_{\mathrm{i}}=$ crescimento das receitas operacionais para cada observação i; e $\varepsilon$, termo de erro que segue uma distribuição normal, com média zero e variância constante.

Vale ressaltar que, com base em Gujarati (2000, p. 566), em modelos com variável dependente dicotômica, o $R^{2}$ é de valor questionável como medida de grau de ajuste. 
Todos esses indicadores econômico-financeiros são índices formados pela divisão de valores em reais ( $\mathrm{R} \$$ ) que compõem as contas dos balanços patrimoniais.

Os indicadores estão divididos nos seguintes grupos:

a. Estrutura: capitalização, imobilização, capital de giro e alavancagem;

b. Solvência: encaixe, cobertura voluntária, liquidez geral e volume de crédito em relação ao patrimônio líquido;

c. Custos e Despesas: despesa de pessoal, despesa administrativa e despesa total;

d. Rentabilidade: geração de renda;

e. Crescimento: crescimento da aplicação total, crescimento da captação total e crescimento das receitas operacionais.

Os indicadores do mesmo grupo contêm informações semelhantes que, juntas, podem não ser significativas. No entanto, não será retirado, a princípio, nenhum dos indicadores, pois a seleção destes para o modelo final será determinada pelos passos definidos para operacionalizar o modelo logit.

\subsection{Procedimentos Operacionais Utilizados para a Regressão Logística}

Visto que as variáveis explicativas possuem identidade de acordo com o grupo a que pertencem, foi adotado o seguinte procedimento para ajustamento do modelo de regressão logística.

\section{Passo 1}

Foram ajustados os modelos com uma única variável de cada vez. As variáveis que foram significativas a 0,10 foram separadas daquelas que não se mostraram significativas individualmente.

\section{Passo 2}


As variáveis significativas no passo 1 foram ajustadas conjuntamente. $\mathrm{Na}$ presença de certas variáveis, outras deixaram de ser significativas. Conseqüentemente, ajustaram-se modelos reduzidos, excluindo-se uma única variável de cada vez. O modelo selecionado foi aquele que teve o maior número de variáveis significativas a 0,10 de significância. Somente aquelas que atingiram a significância permaneceram no modelo.

\section{Passo 3}

As variáveis que não foram significativas no ajustamento do passo 2 foram ajustadas em novo modelo, com vistas a verificar se realmente não são estatisticamente significativas.

\section{Passo 4}

As variáveis ajustadas no passo 3 , que tornaram significativas, retornaram ao modelo ajustado no passo 2. Aquelas que se tornaram significativas permaneceram, caso contrário, foram retiradas do modelo.

\section{Passo 5}

Foi inserida, individualmente, cada uma das variáveis que foram excluídas no passo 1, visando verificar se passaram a ser significativas junto com as demais variáveis significativas. Então, aquelas que se tornaram significativas foram incluídas no modelo, de modo que se oteve um ajustamento com todas as variáveis significativas.

\subsection{Caracterização da Amostra}

Os indicadores econômico-financeiros utilizados neste estudo foram calculados a partir dos balancetes mensais, de agosto 1998 a agosto de 2001, das cooperativas singulares filiadas à CREDIMINAS (Cooperativa Central de Crédito Rural de Minas Gerais Ltda). Essas cooperativas de crédito rural são instituições financeiras autônomas, autorizadas pelo Banco Central, ad-

ministradas pelos próprios produtores associados e integrantes do Banco Cooperativo do Brasil. 
A CREDIMINAS, principal órgão responsável por estas cooperativas, foi constituída, enquanto central das cooperativas de crédito rural do Estado de Minas Gerais, em 1988, e é responsável pela coordenação e centralização dos processos operacionais e pela representação das suas cooperativas filiadas. Sua missão é efetuar a centralização financeira, a fiscalização e o assessoramento nas áreas de crédito, econômica, tecnológica, contábil, de marketing e de comunicação, de organização e métodos, de capacitação profissional e jurídica das Cooperativas de Crédito Rural de Minas Gerais.

Foram disponibilizados dados de 107 cooperativas. Porém, em agosto de 2001 o quadro de filiadas era composto por 103 cooperativas. Vale ressaltar que nas informações disponibilizadas pela CREDIMINAS não há nomes das cooperativas, com o intuito de preservar o sigilo bancário.

As cooperativas existentes no período de 1998 a 2001 são as seguintes: 101 em 1998, 104 em 1999, 107 em 2000, e 103 em agosto de 2001.

As informações fornecidas referiam-se aos meses de agosto de 1998 a agosto de 2001. No entanto, os dados de agosto foram utilizados na formação dos indicadores de crescimento referentes ao mês de setembro. Dessa forma, para operacionalizar os modelos, os indicadores iniciaram em setembro de 1998.

Na realização da previsão de insolvência, por meio do modelo de regressão logística, foram utilizados os dados das 103 cooperativas existentes em agosto de 2001. Na verificação dos indicadores que eram significativos para explicar a insolvência foram utilizadas as informações de dezembro de 2000, buscando analisar um período anterior à ocorrência da insolvência, ou seja, informações anteriores.

Em dezembro de 2000 havia 107 cooperativas. No entanto, como em quatro dessas cooperativas foi constatada ocorrência de insolvência nos anos de 1998 (1), 1999 (2) e 2000 (1), esses dados não foram utilizados porque não correspondiam à ocorrência do evento (insolvência) um tempo atrás. Desse modo, utilizaram-se 11 cooperativas insolventes e 92 solventes. 


\subsection{Operacionalização das Variáveis}

Os indicadores financeiros que constituíram as variáveis explicativas para operacionalização do Modelo Logit foram retirados, em parte, do Manual de Análise, de Austin Asis. Não foram utilizados todos os indicadores, por existir diferença entre as contas dos balanços das cooperativas de crédito rural e das mencionadas no manual da empresa Austin Asis. Desse modo, adequaram-se os indicadores às contas contábeis disponíveis. A sugestão de utilizar esse manual foi extraída dos trabalhos de Matias e Siqueira (1996) e Rocha (1999).

Neste trabalho utilizou-se a análise de série temporal dos índices das cooperativas de crédito de Minas Gerais, pois o que se buscou foi avaliar a situação financeira dessas cooperativas como um todo, e não compará-las entre si com relação à situação de solvência ou insolvência.

Para avaliar quais cooperativas de crédito seriam classificadas como solventes ou insolventes utilizaram-se as informações contábeis disponibilizadas pela CREDIMINAS. As cooperativas classificadas como insolventes foram aquelas que fecharam e/ou que tiveram patrimônio líquido ajustado negativo e/ou o mínimo de $40 \%$ de resultados finais negativos, no período de agosto de 1998 a agosto de 2001; as que não apresentavam tais características foram classificadas como solventes.

Utilizaram-se os seguintes indicadores econômico-financeiros:

\section{Grupo 1 - Indicadores de Estrutura}

a. Capitalização = Patrimônio Líquido/Passivo Real.

b. Imobilização $=$ Ativo Permanente/Patrimônio Líquido.

c. Capital de Giro = Patrimônio Líquido - Ativo Permanente/Patrimônio Líquido.

d. Alavancagem = Captação Total/Patrimônio Líquido. 


\section{Grupo 2 - Indicadores de Solvência}

a. Encaixe $=$ Disponibilidades/Depósitos a Vista.

b. Cobertura Voluntária $=$ Disponibilidades $/$ Passivo Real.

c. Liquidez Geral = Ativo circulante e realizável a longo prazo/Passivo circulante e exigível a longo prazo.

d. Volume de Crédito concedido em relação ao PL = Operações de Crédito/Patrimônio Líquido.

\section{Grupo 3 - Indicadores de Custo e Despesa}

a. Despesa de Pessoal $=$ Despesa de Pessoal/Captação Total.

b. Despesa Administrativa $=$ Despesa Administrativa/Captação Total.

c. Despesa Total $=$ Total das Despesas/Captação Total.

\section{Grupo 4 - Indicador de Rentabilidade}

a. Geração de Renda = Receitas Operacionais/Ativo Real - Ativo Permanente

\section{Grupo 5 - Indicadores de Crescimento}

a. Crescimento da Aplicação Total = Aplicação total do último período/ Aplicação total do período anterior.

b. Crescimento da Captação Total = Captação total do último período/ Captação total do período anterior.

c. Crescimento da Receita Operacional = Receita operacional do último período/Receita operacional do período anterior. 


\section{Indicadores Utilizados nos Cálculos Anteriores}

a. Ativo Real $=$ Ativo total - Relações interfinanceiras - Relações interdependências.

b. Passivo Real = Passivo total - Relações interfinanceiras - Relações interdependências.

c. Aplicação Total $=$ Ativo Real - Ativo permanente - Diversos.

d. Captação Total $=$ Passivo Real - Patrimônio Líquido - Diversos .

Na operacionalização do modelo de regressão logística a variável dependente admitia valor zero quando a cooperativa era classificada como solvente, $\mathrm{e}$ valor 1, quando insolvente. Utilizaram-se dados de dezembro de 2000 para avaliar quais seriam os indicadores preditores de insolvência, e de agosto de 2001, para realizar a previsão de insolvência das cooperativas de crédito rural do Estado de Minas Gerais.

\subsection{Fonte dos Dados}

Os indicadores financeiros foram calculados a partir dos balancetes mensais, de agosto de 1998 a agosto de 2001, das 107 cooperativas de crédito rural, singulares, filiadas à CREDIMINAS. Essa base de dados foi disponibilizada pela CREDIMINAS (Cooperativa Central de Crédito Rural de Minas Gerais Ltda.), que é o órgão de cúpula do SICOOB-MG (Sistema Integrado das Cooperativas de Crédito Rural de Minas Gerais).

\section{ANÁLISE E DISCUSSÃO DOS RESULTADOS}

A análise e discussão dos resultados está divida em três partes: na primeira serão retratados os indicadores financeiros das cooperativas de crédito rural de Minas Gerais, no período de 1998 a 2000; na segunda, discutir-se-ão os indicadores que foram importantes para informar a situação de insolvência. 


\subsection{Fatores que Influenciaram a Ocorrência de Insolvência das Coope-} rativas de Crédito Rural do Estado de Minas Gerais

Antes de abordar diretamente o resultado do modelo é importante recordar os parâmetros que determinaram a insolvência nas cooperativas de crédito rural de Minas Gerais, mostrando o número de cooperativas, por mês, que tiveram ocorrência de insolvência, assim como os procedimentos que foram adotados para realizar a previsão de insolvência.

As cooperativas classificadas como insolventes foram as que fecharam e/ou apresentaram patrimônio líquido ajustado (PLA) negativo no período de 37 meses e/ou apresentaram $40 \%$ ou mais de resultados finais (RF) negativos. Determinou-se que a ocorrência seria registrada no mês do fechamento e que, no último mês, fosse constatado o PLA negativo e/ou o $\mathrm{RF}^{4}$ negativo, de acordo com a base de dados fornecida pela CREDIMINAS. Segundo essas informações, foram observadas as ocorrências registradas na Tabela 1.

Observando-se os dados da Tabela 1 verifica-se que no ano de 2001 foram registrados $73,33 \%$ casos de cooperativas classificadas como insolventes. Nesse sentido, procurou-se analisar a previsão de insolvência ajustando-se o modelo de regressão logística a um passo atrás (2000), com o intuito de verificar quais seriam os indicadores preditores de insolvência. Nessa avaliação foram utilizados dados de dezembro de 2000. Com base nos dados de agosto de 2001, foi feita a previsão de insolvência de 103 cooperativas de crédito rural de Minas Gerais, filiadas à CREDIMINAS.

4 RF negativo, seguindo o porcentual acima estabelecido de ocorrência em mais de $40 \%$ do período. 
TABELA 1 - NÚMERO DE COOPERATIVAS DE CRÉDITO RURAL NO ESTADO DE MINAS GERAIS E DATA DA OCORRÊNCIA DO EVENTO - INSOLVENNCIA, NO PERÍODO DE SETEMBRO DE 1998 A AGOSTO DE 2001

\begin{tabular}{lccc}
\hline Registro de insolvência & N.. de cooperativas & Porcentual & $\begin{array}{c}\text { Porcentual } \\
\text { por ano }\end{array}$ \\
\hline Setembro-1998 & 1 & 6,67 & $1998=6,67$ \\
Março-1999 & 1 & 6,67 & $1999=13,33$ \\
Julho-1999 & 1 & 6,67 & \\
& & & \\
Junho-2000 & 1 & 6,67 & $2000=6,67$ \\
& & & \\
Janeiro-2001 & 1 & 6,67 & $2001=73,33$ \\
Fevereiro-2001 & 1 & 6,67 & \\
Abril - 2001 & 1 & 6,67 & \\
Maio-2001 & 1 & 6,67 & \\
Junho-2001 & 1 & 6,67 & \\
Julho-2001 & 2 & 13,33 & \\
Agosto-2001 & 4 & 26,67 & \\
Total & & & \\
\hline
\end{tabular}

Fonte: Dados da pesquisa.

Constata-se que o modelo ajustado apresentou 97,09\% de classificação correta das cooperativas. Das 11 cooperativas insolventes, com o ponto de corte de 0,5 , nove foram captadas pelo modelo, o que indica um nível de acerto de $81,82 \%$ para cooperativas insolventes. Nas cooperativas solventes, o modelo apresentou $98,91 \%$ de classificação correta. De modo geral, o modelo apresentou bom ajuste, em termos de tabela de expectativa de predição (Tabela 2). 
TABELA 2 - SITUAÇÃO DAS COOPERATIVAS DE CRÉDITO RURAL NO ESTADO DE MINAS GERAIS, EM DEZEMBRO DE 2000, VERSUS CLASSIFICAÇÃO DESTAS COOPERATIVAS PELO MODELO

\begin{tabular}{ccc}
\hline Situação da cooperativa & $\begin{array}{c}\text { Classificação da cooperativa } \\
\text { pelo modelo }\end{array}$ & $\begin{array}{c}\text { Porcentual parcial de classifi- } \\
\text { cação correta do modelo }\end{array}$ \\
\cline { 2 - 3 } & Solvente Insolvente \\
\hline
\end{tabular}

$\begin{array}{lccc}\text { Solvente } & 91 & 1 & 91 / 92=98,91 \% \\ \text { Insolvente } & 2 & 9 & 9 / 11=81,82 \%\end{array}$

Porcentual total de classificação correta do modelo

$(91+9) / 103=97,09 \%$

Fonte: Dados da pesquisa.

As variáveis que influenciaram a insolvência, com base nos dados de dezembro de 2000, foram capitalização, cobertura voluntária, despesa administrativa e crescimento da captação total, todas significativas a $10 \%$ de probabilidade, e apenas o indicador de despesa administrativa apresentou sinal contrário ao esperado (Tabela 3). Calculou-se, também, a matriz de correlação entre essas variáveis e constatou-se que a intensidade ou o grau de associação linear entre as variáveis foi baixa.

A capitalização informa a relação entre o valor do patrimônio da cooperativa e suas obrigações; quanto maior esse índice, melhor a situação financeira das cooperativas. Nesse sentido, esse indicador apresentou sinal negativo, porque quanto maior a capitalização, menor a probabilidade de a cooperativa entrar em estado de insolvência. O efeito marginal de $-1,45$ informa que a variação de uma unidade na capitalização causa variação, em sentido contrário, de 1,45 pontos porcentuais na probabilidade de a cooperativa de crédito rural de Minas Gerais tornar-se insolvente (Tabela 3). 
TABELA 3 - COEFICIENTES ESTIMADOS PELO MODELO LOGIT PARA VERIFICAR INSOLVÊNCIA NAS COOPERATIVAS DE CRÉDITO RURAL NO ESTADO DE MINAS GERAIS, REFERENTE A DEZEMBRO DE 200 '

\begin{tabular}{lrrrrr}
\hline Variável & Coeficiente & $\begin{array}{l}\text { Desvio } \\
\text { padrão }\end{array}$ & Estatística Z & Valor P & $\begin{array}{c}\text { Efeito } \\
\text { marginal }^{5}\end{array}$ \\
\hline Constante & $-28,54345$ & 16,92108 & $-1,686857$ & 0,0916 & - \\
Capitalização & $-15,18026$ & 8,456479 & $-1,795105$ & 0,0726 & $-1,4481$ \\
Cobertura voluntária & $-25,76486$ & 8,198181 & $-3,142753$ & 0,0017 & $-22,4577$ \\
Despesa administrativa & $-94,58213$ & 50,15836 & $-1,885670$ & 0,0593 & $-9,0222$ \\
Crescim. da captação total & 33,48694 & 17,35518 & 1,929506 & 0,0537 & 3,19434
\end{tabular}

Fonte: Dados da pesquisa.

O indicador de capitalização não foi significativo no trabalho de previsão de insolvência bancária de Matias e Siqueira (1996), que utilizaram informações de 16 bancos que sofreram liquidações ou intervenção do Banco Central no período de julho de 1994 a março de 1995 (bancos insolventes), e um grupo de controle de 20 bancos solventes, de grande porte, não-públicos. Nesse trabalho, os autores questionaram a validade do Acordo da Basiléia e de medidas do Banco Central sobre a obrigatoriedade de capitalização e capital mínimo das instituições financeiras atuantes no Brasil, uma vez que o indicador em questão não foi significativo para determinar a insolvência bancária.

No caso das cooperativas de crédito rural singulares, o capital mínimo integralizado na data de autorização para funcionamento da cooperativa deve ser de RS 3.000,00 (três mil reais), e o patrimônio líquido, ajustado após três anos da referida data de autorização de funcionamento, deve ser de R $\$$ $30.000,00$, e após cinco anos, de R $\$ 60.000,00$ (Resolução 2.771 , art. $5^{\circ}$ ).

5 O efeito marginal de $X$ mede a inclinação da curva no ponto considerado, ou seja, é a derivada da variável dependente em relação à variável explicativa. 
Constata-se que, no caso das cooperativas de crédito rural do Estado de Minas Gerais, diferentemente dos bancos, é pertinente a validade do Acordo da Basiléia e das medidas do Banco Central, uma vez que o indicador de capitalização foi significativo para determinar a insolvência nessas cooperativas.

A cobertura voluntária mostra a relação das disponibilidades sobre o passivo real, ou seja, indica o porcentual de ativo de curto prazo em relação às obrigações das cooperativas. O sinal negativo foi coerente com o esperado, pois quanto maior a cobertura voluntária, menor a possibilidade da ocorrência de insolvência. O efeito marginal de $-22,46$ indica que uma variação de uma unidade na cobertura voluntária provoca, em sentido contrário, variação de 22,46 pontos porcentuais na probabilidade de ocorrência de insolvência (Tabela 3 ).

O indicador de crescimento da captação total foi significativo, tanto para determinar a insolvência nas cooperativas de crédito rural quanto para determinar a insolvência bancária, conforme trabalho de Matias e Siqueira (1996). Esse indicador mostra a taxa de crescimento da captação total de recursos do mês anterior em relação ao mês posterior. $\mathrm{O}$ aumento da captação indica que a cooperativa está demandando mais recursos e, provavelmente, maior será a taxa exercida pela instituição fornecedora de recursos.

Esse indicador apresentou sinal positivo, porque quanto maior o crescimento da captação total, considerando-se o aumento da utilização de recursos de terceiros, maior será a probabilidade de a cooperativa entrar em estado de insolvência. O efeito marginal de 3,19 informa que a variação de uma unidade na captação total causa variação no mesmo sentido de 3,19 pontos porcentuais na probabilidade de as cooperativas de crédito rural de Minas Gerais tornarem-se insolventes (Tabela 3).

A despesa administrativa foi outro indicador significativo para avaliar a ocorrência de insolvência, como também foi significativa no trabalho de Matias e Siqueira (1996), que relataram que quanto maior o custo administrativo, maior a probabilidade de insolvência.

Entretanto, esse indicador não apresentou sinal coerente com o esperado, já que, como constataram os autores citados, era de esperar que quanto maior 
as despesas administrativas, maior seriam as chances de as cooperativas tornarem-se insolventes. No caso das cooperativas de crédito rural, com base nos dados de dezembro de 2000, uma variação de uma unidade na despesa administrativa causaria variação, no sentido contrário, de 9,02 pontos porcentuais na probabilidade de as cooperativas se tornarem insolventes, indicando que quanto maior a despesa administrativa, menor a probabilidade de insolvência, fato que, de modo geral, não é observado na prática (Tabela 3 ).

Ao se avaliar o porquê de o sinal do indicador de despesa administrativa não ter sido coerente com o esperado, verificou-se que, pelos dados do referido indicador, em dezembro de 2000, dos valores observados nas 103 cooperativas de crédito rural em $97,09 \%$ destas o indicador de despesa administrativa encontrava-se acima de $-0,3$, ou seja, a maior parte dos índices de despesa administrativa representava menos de $3 \%$ da captação total, podendo considerar pequeno o volume de despesas administrativas em relação ao volume de captação da cooperativa. Dessa forma, acredita-se que, devido a esses baixos porcentuais, o modelo logit não tenha captado a influência direta dessas despesas na indicação de insolvência (Tabela 4).

TABELA 4 - VALORES OBSERVADOS PARA O INDICADOR DE DESPESA ADMINISTRATIVA DAS COOPERATIVAS DE CRÉDITO RURAL NO ESTADO DE MINAS GERAIS, EM DEZEMBRO DE 2000

\begin{tabular}{lccl}
\hline Índices observados & N. ${ }^{-}$de cooperativas & Porcentual & \multicolumn{1}{c}{ Porcentual por grupos } \\
\hline$-0,12$ & 1 & 0,97 & $\begin{array}{l}\text { Entre índices }-0,04 \text { e }-0,12= \\
2,91 \%\end{array}$ \\
$-0,5$ & 1 & 0,97 & \\
$-0,4$ & 1 & 0,97 & \\
$-0,3$ & 11 & 10,68 & Entre índices $-0,01$ e $-0,03=$ \\
& & & \\
$-0,2$ & 50 & $48,09 \%$ & \\
$-0,1$ & 39 & 37,86 & \\
Total & 103 & 100,00 & \\
\hline
\end{tabular}

Fonte: Dados da pesquisa. 
Por outro lado, um aumento da despesa administrativa, visando à melhoria da estrutura da cooperativa, acompanhada de avaliações do potencial das cooperativas de cumprir com esses custos, pode não levar à insolvência. Kanitz (1978) destaca que nem toda empresa irá, obrigatoriamente, à falência por estar enfrentando dificuldades em determinado momento. Afinal, qualquer empresa bem administrada pode recuperar-se de uma situação difícil. Portanto, o fator de insolvência é um indicador daquilo que pode acontecer num futuro próximo, caso a empresa não corrija os rumos que está seguindo.

Outro ponto que pode ser destacado é que quanto menor o indicador de despesa total, menores serão as necessidades de aumento da captação total. Um dos fatos que levam à insolvência é o aumento da captação total, considerando-se o aumento da necessidade de capital de terceiros. No caso em questão, como o volume da despesa administrativa é relativamente pequeno se comparado ao volume de captação, é possível aumentar um pouco as despesas administrativas sem se incorrer em insolvência. Entretanto, é de fundamental importância avaliar o montante de captação total de cada cooperativa em relação ao seu número de associados.

Apesar de o modelo ajustado a um passo atrás ter apresentado um indicador com sinal contrário ao esperado, de modo geral esse modelo apresentou bom ajuste total: da ordem de $97,09 \%$ (Tabela 2). Dessa forma, esse ajuste foi utilizado na previsão das cooperativas de crédito rural, com base nos indicadores de agosto de 2001.

O resultado da previsão para as 103 cooperativas de crédito rural do Estado de Minas Gerais, com base no ponto de corte de 0,5 , foi de duas cooperativas insolventes e 101 cooperativas solventes em agosto de 2001. As duas cooperativas insolventes apresentaram as seguintes características: o índice de geração de renda não apresentou diferenças entre as duas cooperativas insolventes; os índices de crescimento da captação total e crescimento da aplicação total apresentaram diferença de 0,03 ; no entanto, a cooperativa 01 teve decréscimo tanto na captação quanto na aplicação total, em agosto de 2001, enquanto a cooperativa 02 apresentou crescimento tanto na aplicação total quanto na captação total de 1\% relativamente ao mês de julho de 2001 (Tabela 5). 
A imobilização e o capital de giro apresentaram diferença, nos índices, de 0,06; a cooperativa 02 teve imobilização maior e capital de giro menor que a cooperativa 01 . Com relação à receita operacional, constatou-se decréscimo na cooperativa 02 e crescimento de $5 \%$ na cooperativa 01 relativamente ao mês de julho de 2001. A cobertura voluntária, em ambas as cooperativas, ficou abaixo de $15 \%$, ou seja, o volume de ativo no curto prazo em relação ao passivo real foi de $1 \%$ na cooperativa 02 e de $11 \%$ na cooperativa 01 (Tabela 5).

TABELA 5 - CARACTERÍSTICAS DAS COOPERATIVAS INSOLVENTES, COM BASE NOS DADOS DE AGOSTO DE 2001

\begin{tabular}{lcc}
\hline Indicadores & \multicolumn{2}{c}{ Valores } \\
\cline { 2 - 3 } & Cooperativa 01 & Cooperativa 02 \\
\hline Capitalização & 0,14 & 0,33 \\
Imobilização & 0,27 & 0,33 \\
Capital de giro & 0,73 & 0,67 \\
Alavancagem & 6,63 & 2,57 \\
Encaixe & 0,98 & 0,04 \\
Cobertura voluntária & 0,11 & 0,01 \\
Liquidez geral & 1,11 & 1,24 \\
Volume de crédito em relação ao PL & 6,25 & 1,43 \\
Despesa de pessoal & $-0,004$ & $-0,01$ \\
Despesa administrativa & $-0,01$ & $-0,02$ \\
Despesa total & $-0,02$ & $-0,03$ \\
Geração de renda & 0,02 & 0,02 \\
Crescimento da aplicação total & 0,99 & 1,01 \\
Crescimento da captação total & 0,98 & 1,01 \\
Crescimento da receita operacional & 1,05 & 0,98 \\
\hline
\end{tabular}

Fonte: Dados da pesquisa.

A liquidez geral, apesar de maior que 1 em ambos os casos, caracterizou estado de insolvência. Esses dados reforçam a afirmação de Kanitz (1978), de 
que, ao contrário do que se costuma pensar, os índices de liquidez não são um indicador seguro do estado de solvência das empresas. A capitalização apresentou uma diferença, em termos de índice, de 0,19. Já o indicador de encaixe, que avalia o valor de ativos no curto prazo e passivo no curto prazo, apresentou diferença de 0,94 entre as cooperativas 01 e 02, no entanto, em ambos os casos os valores em disponibilidades foram menores que os valores em depósitos a vista (Tabela 5).

Os índices de alavancagem informam que em ambas as cooperativas a captação total superou duas vezes o patrimônio líquido, ou seja, é preciso atentarse para as características da captação dessas cooperativas, pois quanto maior o crescimento da captação total, maiores serão as possibilidades de insolvência. $\mathrm{O}$ volume de crédito em relação ao patrimônio líquido, também em ambas cooperativas insolventes, superou o valor do patrimônio; o que precisa ser avaliado, neste caso, é se os cooperados estão saldando suas dívidas com as cooperativas. De modo geral, as despesas foram, em média, de $1 \%$ da captação total (Tabela 5 ).

Vale ressaltar que havia quatro cooperativas classificadas como insolventes (ver Tabela 1); no entanto, duas destas foram fechadas, de modo que os dados dessas cooperativas não se encontravam entre os das 103 cooperativas de crédito rural em agosto de 2001. Pode-se verificar que o modelo ajustado a um passo atrás, com dados de dezembro de 2000, apresentou excelente resultado de previsão de insolvência.

Dessa forma, constata-se que as cooperativas de crédito rural de Minas Gerais filiadas à CREDIMINAS não se encontravam em estado de insolvência. Apenas duas cooperativas (1,94\%), cujo ponto de corte era de 0,5 , apresentavam probabilidade de insolvência, e 101 cooperativas $(98,06 \%)$, probabilidade de solvência. 


\section{CONCLUSÕES}

Este trabalho vem realçar a importância do cooperativismo de crédito rural, um setor da economia que, nos últimos anos, vem crescendo, e de acordo com as estruturas financeiras analisadas, possivelmente atendendo à demanda de crédito por parte do produtor rural, ou mesmo administrando bem os recursos que são repassados pelo governo federal.

É importante enfatizar que apesar de o cooperativismo de crédito em Minas Gerais estar apresentando bom desempenho, é aconselhável que os produtores rurais, assim como os dirigentes das cooperativas, estejam atentos especialmente aos indicadores de capitalização, cobertura voluntária e crescimento da captação total, porque tais indicadores econômico-financeiros, de acordo com o modelo ajustado para o ano de 2000 , foram importantes para a predição de insolvência e apresentaram sinais coerentes com os esperados.

É preciso alertar, no entanto, que a ocorrência de mudanças estruturais, administrativas, políticas ou mesmo de conjuntura econômica pode acarretar mudança nos indicadores mais representativos para prever a insolvência.

Por outro lado, é importante afirmar que a ocorrência de fechamento de cooperativas, que forneceria a informação ex-post para a pesquisa, é muito pequena se comparado com os bancos comerciais. Isto porque no sistema cooperativista ocorre ajuda mútua entre cooperativas, fato que, de certa forma, promove a manutenção de cada cooperativa.

É importante ressaltar, ademais, que o modelo logit possui limitações. Apresenta um resultado estático, ou seja, mudando as condições, tais como as políticas econômicas, a estrutura administrativa nas cooperativas, os períodos de recessão econômica, os problemas com desonestidade administrativa, entre outros fatores, é possível que ocorram alteraçôes nos indicadores preditores de insolvência ou mesmo mudança em seus pesos. Assim sendo, esse modelo não pode ser aplicado indefinidamente para vários anos, sem um procedimento adaptado.

Recomenda-se, para trabalhos futuros, relacionar os indicadores financeiros de cooperativas de crédito rural de Estados diferentes com intuito de reali- 
zar comparações e a fim de verificar os parâmetros que possam classificar os indicadores como bons ou ruins para as cooperativas.

Uma recomendação final consiste em operacionalizar o modelo logit com diferentes cenários com o propósito de verificar quais seriam os indicadores mais representativos para indicar a insolvência, pois eles podem sofrer alteraçôes de um ano para outro. A estimativa do modelo exigirá, mantendo-se a metodologia, a existência de um grupo de cooperativas solventes e outro de cooperativas insolventes.

\section{REFERÊNCIAS BIBLIOGRÁFICAS}

ALBUQUERQUE JR., J.; RIBEIRO, Eduardo P. Avaliação dos indicadores de predição de insolvência bancária no brasil para os períodos de 1994/95 e 1997/98: uma análise de robustez. In: XXVIII Encontro Nacional de Economia, 2001, Salvador-BA. Anais.... ANPEC, 2001. v. 1, p. 1-21 (CD-ROM).

ALMEIDA, F. C.; SIQUEIRA, J. O. Comparação entre regressão logística e redes neurais na previsão de falência de bancos brasileiros. Terceiro Congresso Brasileiro de Redes Neurais, 4. Florianópolis, 1997, p. 1-6.

ALMEIDA, F. C. L'evaluation des risques de défaillance des entreprises à partir des réseaux de neurones insérés dans les systèmes d’aide à la décision. Ecole Supérieure des Affaires. 1993. 255p. Thèse (Doctorat en Sciences de Gestion) - Université Pierre Mendès France de Grenoble.

ALTMAN, E. I.; BAIDYA, T. K. N.; DIAS, L. M. R. Previsão de problemas financeiros em empresas. Revista de Administração de Empresas, v. 19, n. 1, p 17-28, jan/mar, 1979.

ALTMAN, E. I. Financial ratios, discriminant analysis and the prediction of corporation bankruptcy. Journal of Finance, v. 23, n. 4, p. 589609, 1968.

ASSAF NETO, A. Estrutura e análise de balanços - um enfoque econômicofinanceiro. São Paulo: Atlas, 1981. 219 p.

BACKER, M.; GOSMAN, M. L. Financial reporting and business liquidity. New York: National Association of Accountants, 1978.

BANCO CENTRAL DO BRASIL - BCB. Os princípios essenciais da Basiléia. Disponível em: www.bcb.gov.br, 12 dez. 2001.

BELIK, W., PAULILLO, L. F. Mudanças no financiamento da produção agricola brasileira. Disponível em: www.rlc.fao.org/prior/desrural/ brasil/ Belik.PDF, 22 abr. 2002. 
BERZOINI, R.; SOUZA, P. A. Idéias para um sistema cooperativa de crédito. Gazeta Mercantil, São Paulo, 17 abr. 2001, p. A3.

CARCANHOLO, M. D. Desregulamentação e abertura financeiras: repercussões sobre autonomia de política econômica e as crises cambiais. (redem.buap.mx/acrobat/marcelol.pdf). (22 abr. 2002).

CARVALHO, F. M. A. Crédito rural no Brasil: evolução, resultados e perspectivas. In: SANTOS, M. L.; VIEIRA, W. C. (eds.), Agricultura na virada do milênio, velhos e novos desafios. Viçosa, 2000. p. 77 91.

DAILY, C. M.; DALTON, D. R. Corporate governance and the bankrupt firm: an empirical assessement. Strategic Management Journal, v. 15, p. $643-654,1994$.

ESPAHBODI, P. Identification of problem banks and binary choice models. Journal of Banking and Finance, n. 15, p. 53-71, 1991.

GASQUES, J. G.; VILA VERDE, C. M. Novas fontes de recursos, propostas e experiências de financiamento rural. Revista de Economia e Sociologia Rural, v. 34, n. 3 e 4, p 39-80, jul/dez 1996.

GIMENES, K. M. I. Análise do comportamento dos administradores financeiros com respeito ao custo e estrutura de capital aplicado as cooperativas agropecuárias do Estado do Paraná. 1998. 338p. Tese (Doutorado), Universidade de León, Espanha.

GITMAN, L. J. Princípios de administração financeira. $7^{\circ}$ Edição. São Paulo: Habra, 1997. 841p.

GUJARATI, D. N. Econometria básica. $4^{\mathrm{a}}$ ed. São Paulo: Makron Books, 2000. 846 p.

JANOT, M. M. Modelos de previsão de insolvência bancária no Brasil. Trabalho para discussão, Brasília, n. 13, mar/2001, p. 1-40. Disponível em: www. bcb.gov.br

JANOT, M. M. Modelos de previsão de insolvência bancária no Brasil: aplicação de diferentes modelos entre 1995 e 1998. 1999. 94p. Dissertação (Mestrado), Pontifícia Universidade Católica do Rio de Janeiro.

KANITZ, S. C. Como prever falências. São Paulo: McGraw-Hill, 1978.

KENNEDY, P. A guide to econometrics. Oxford: Blackwell Publishers, 1994. 410p.

MARTIN, D. Early warning of banking failure - a logit regression approach. Journal of Banking and Finance, v.1, p. 249-276, 1977.

MARTINS, M. S. A previsão de insolvência pelo modelo de Cox: uma contribuição para a análise de companhias abertas brasileiras. 2003. 102p. Dissertação (Mestrado) Universidade Federal do Rio Grande do Sul, Porto Alegre. 
MATIAS, A. B.; SIQUEIRA, J. O. Risco bancário: modelo de previsão de insolvência de bancos no Brasil. Revista de Administração, São Paulo, v. 31, n. 2, p. 19-28, abril/junho 1996.

MUÑOZ, J. Calidad de cartera del sistema bancario y el ciclo económico: una aproximación econométrica para el caso peruano. Disponível em: www.bcrp.gov.pe/espanol/publicaciones/Revista/Revjul99/ tema5.pdf. (10 maio 2001).

PANDELÓ JR., D. R. Avaliação de riscos de instituiçôes financeiras com base em dados contábeis. Belo Horizonte, 1997. (Texto não publicado).

ROCHA, F. Previsão de falência bancária: um modelo de risco proporcional. Pesquisa e Planejamento Econômico, Rio de Janeiro, v. 29, n. 1, p. 137-152, 1999.

ROLANDO, H. A.; MEZA, R. A.; LOW, L. A.; TERRAZA, E. G.; MARIA, M. S.; HEWSTONE, E. V. Manual de administración y financiamento cooperativo. Argentina>Intercoop, 1981. 127p. (Série Manuales, 10).

SILVA, J. P. Administração de crédito e previsão de insolvência. São Paulo: Atlas, 1983. 139p. . Análise e decisão de crédito. São Paulo: Atlas, 1988. 297p.

TZIRULNIK, L. Intervenção e liquidação extrajudicial das instituições financeiras. $3^{\text {a }}$ Ed. São Paulo: Revista dos Tribunais, 1997, 429p. 